s Research Square

\title{
Estimation of The Fractal Dimension of Thyroid Nodules As A Complementary Diagnostic Tool For Predicting Malignancy
}

Philippe Lothaire ( $\nabla$ philippe.lothaire@chu-charleroi.be)

$\mathrm{CHU}$ Charleroi

Pierrick Uzureau

Université libre de Bruxelles, CHU Charleroi

Karim Zouaoui Boudjelta

Université libre de Bruxelles, CHU Charleroi

Nathalie Nagy

CHU Charleroi

Carine Michiels

URBC, NARILIS

Timoteo Carletti

NARILIS

\section{Research Article}

Keywords: Cancer, Thyroid nodules, Ultrasonography, Fractal dimension, Image analysis

Posted Date: May 25th, 2021

DOI: https://doi.org/10.21203/rs.3.rs-504905/v1

License: (1) This work is licensed under a Creative Commons Attribution 4.0 International License.

Read Full License 


\section{Estimation of the fractal dimension of thyroid nodules as a complementary diagnostic tool for predicting malignancy}

Philippe LOTHAIRE, MD ${ }^{1 * *}$, Pierrick UZUREAU, PhD², Karim ZOUAOUI BOUDJELTA, PhD², Nathalie NAGY, MD³ , Carine MICHIELS, $\mathrm{PhD}^{4 *}$, Timoteo CARLETTI, $\mathrm{PhD}^{5 *}$

${ }^{1}$ Department of Head and Neck Surgery, CHU Charleroi, Belgium

${ }^{2}$ Laboratory of Experimental Medicine (ULB 222), Medicine Faculty, Université libre de Bruxelles, CHU Charleroi, Belgium

${ }^{3}$ Department of Pathology, CHU Charleroi, Belgium

${ }^{4}$ Department of Biology, URBC, NARILIS, UNamur, Belgium

${ }^{5}$ Department of Mathematics, Naxys, NARILIS, UNamur,Belgium

* These authors codirected equally this study

${ }^{* *}$ corresponding author : Philippe LOTHAIRE, Department of Head and Neck Surgery, CHU Charleroi, 6110 Montigny le Tilleul, Belgium philippe.lothaire@chu-charleroi.be 


\section{Abstract}

\section{Purpose}

Ultrasound-guided fine-needle aspiration is the most sensitive investigation procedure in the evaluation of patients with thyroid nodules; however, despite the level of achieved precision, it is still impossible to preoperatively discriminate between follicular adenomas and carcinomas. Thus, no current detection tool of thyroid nodule has both high sensitivity and high positive predictive value for the diagnosis of thyroid cancer. Ultrasound images provide information that are currently missed due to visual interpretation, including the roughness of the echotexture. However, such information can be retrieved using the measurement of the fractal dimension (FD).

\section{Material and methods}

According to the box-counting method, we measured the FD of the echotexture of ultrasound images of 13 benign thyroid nodules and 14 malignant thyroid nodules compared to normal thyroid tissue from 10 men and 16 women (mean age 40).

\section{Results}

The difference of the FD value between malignant nodules (median FD 2.31) and corresponding normal tissues (median FD 2.184) was significant $(\mathrm{p}<0.001)$ while the FD values for the benign nodules (median FD 2.21) and for corresponding normal tissues (median FD 2.231) could not be distinguished $(\mathrm{p}=0.78)$.

\section{Conclusions}

This preliminary work revealed that FD would be an additional feature to discriminate benign from malignant nodules. A larger sampling is now required to confirm the possible utilization of FD in the thyroid cancer diagnosis in clinical practice. 


\section{$\underline{\text { Keywords }}$}

Cancer; Thyroid nodules; Ultrasonography; Fractal dimension; Image analysis 


\section{$\underline{\text { Introduction }}$}

Thyroid cancer remains rare but its incidence increased due to the better detection of small papillary cancers (1). Thus, ultrasound (US) imaging of the thyroid is increasingly performed and can detect nodules as small as $0.2 \mathrm{~cm}$ (2). Sonographic features for discriminating benign and malignant nodules have been extensively studied but no single parameter satisfactorily identifies the subset of patients which diagnosis requires the fine-needle aspiration biopsy (FNAB) (3). The Thyroid Imaging Reporting and Data System (TIRADS) is a standardized tool designed to avoid unnecessary FNAB (4). The TIRADS implements a large number of US patterns (echogenicity, echostructure, shape, borders, calcifications, vascularization) to improve the clinical power of US to discriminate nodules. However even with such standardization, the inter-individual variability among radiologists and the use of different US devices impairs the reproducibility of the conclusions $(5,6)$. Similarly, ultrasound elastography which analyses the stiffness of the nodules could discriminate malignant from benign lesions but this technique requires an additional procedure and lacks reproducibility (7). Papillary and follicular thyroid carcinomas are well-differentiated thyroid carcinomas and represent about $95 \%$ of all thyroid cancers. While US discrimination between benign and malign nodules has been reported in the case of papillary carcinoma, the sonographic features of follicular adenoma and follicular carcinoma are very similar and as a consequence, follicular carcinoma diagnosis using US is still challenging (8).

Fractal analysis has already many applications in the field of medicine; one of them is the analysis of anatomic structures such as vascular or bronchial trees (9) or the haemodynamic effects of several types of diseases $(10,11)$. A fractal structure is characterized by a fractal dimension (FD) allowing for a quantitative assessment of parameters such as heterogeneity, irregularity or complexity. Several image analysis techniques have been published in order to characterize pathological tissues such as abnormal liver tissue or endobronchial nodes $(12,13)$. 
Hereby, we computed the FD of ultrasound images in order to determine if differences between normal tissue, benign and malignant thyroid nodules could be evidenced. The image requirements to draw accurate results are also investigated. 



\section{$\underline{\text { Results }}$}

$\underline{\text { Algorithm design and validation on reference images }}$

We have developed dedicated algorithm which approximated the FD of a given image using the box-counting method. We benchmarked the algorithm on synthetic images whose FD is explicitly computable, namely the Sierpinski triangle $(\log 3 / \log 2=1.585)$, the Sierpinski carpet $(\log 8 / \log 3=1.8928)$ and the dragon curve $(\log 2 / \log \sqrt{2}=2)$ and on the D03 texture image from the Brodatz album which estimated FD ranged from 2.60 to 2.69 (15) (Fig. 2). The FD values of the Sierpinski triangle, the Sierpinski carpet and the dragon curve measured by the algorithm strictly corresponded to the theoretical values (Fig. 3). The FD value of 2.66 measured for the D03 Brodatz image was within the previously published range (14) (Fig. 3).

a

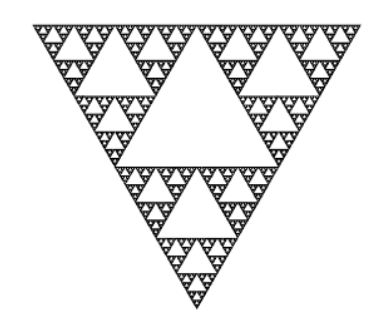

C

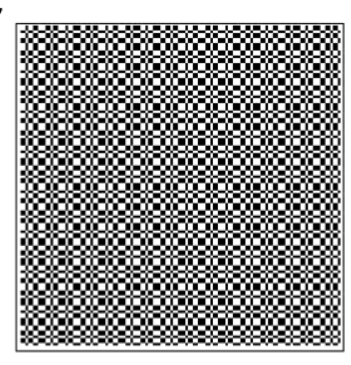

b

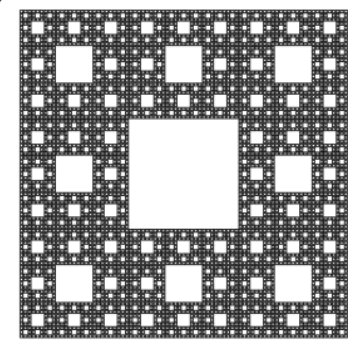

d

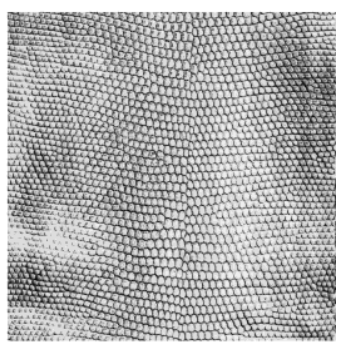

Figure 2: Figures selected to validate the algorithm

(a) The Sierpinski triangle was built starting from a full equilateral triangle, divided into 4 equals smaller triangles and then, removing the "central one". Iterating this process yields a structure whose theoretical FD is 1.585 . (b) The Sierpinski carpet was obtained by dividing a square into 9 smaller squares and then removing the "central one". The structure obtained by iterating the previous construction will have a theoretical FD of 1.89. (c) The Dragon curve is a space-filling 
curve with a theoretical FD of 2.0. (d) The grayscale texture D03 which belongs to the standard Brodatz texture album has a FD varying from 2.60 till 2.69 (15).
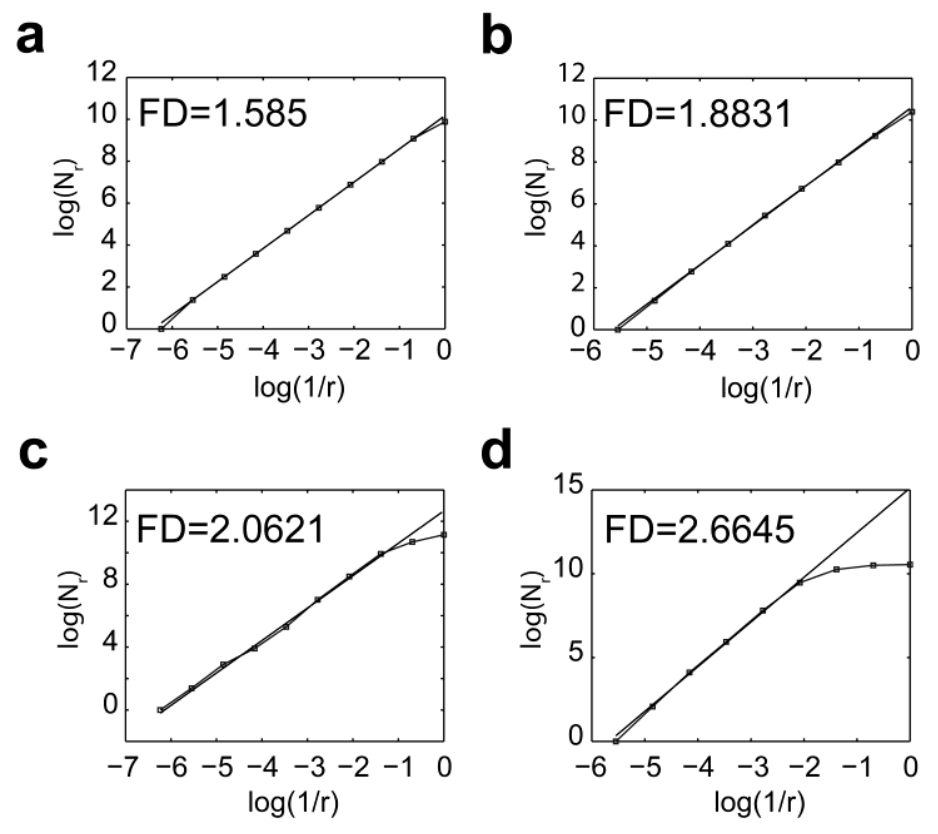

\section{Lothaire et al., Figure 3}

Figure 3: Measurement of the FD of reference images using the algorithm

The FD values of the Sierpinski triangle (a), the Sierpinski carpet (b), the Dragon curve (c) and the Brodatz D03 texture $(\mathrm{d})$ were calculated using the box counting method. The number of boxes $(\mathrm{N})$ required to cover the whole image is plotted against the reduction factor ( $\mathrm{r}$ ) of the box sizes between each iteration of the analysis. The linear best fit of the $\log (\mathrm{N})=\mathrm{f}(\log (1 / \mathrm{r}))$ curve whose slope corresponds to the FD is represented.

\section{Algorithm validation according the size of images}

When assayed on the Brodatz D03 texture image using different resolutions, the algorithm gave reproducible and reliable values of the FD of the image (Fig. 4a). This suggested that the reduction of the resolution did not affect the result of the computed FD. We also observed that reducing the image size altered the accuracy of the FD measure which reached a plateau when image surface was greater than 10000 pixels $^{2}$ (Fig. 4a). When using the same image with different $\mathrm{H} / \mathrm{L}$ ratio, we observed that a minimum height of 80 pixels was required for accurate FD measurement (Fig. 4b). Image size limitations were confirmed on US images of normal tissue (Fig. 5a), benign nodule (Fig. 5b) and a malignant nodule (Fig. 5c) at different sizes. The threshold value 
for the size of the image required to limit FD variability to $5 \%$ started at 7000 pixels $^{2}$ for the normal tissue and 10000 pixels $^{2}$ for both nodules (Fig. 5d).

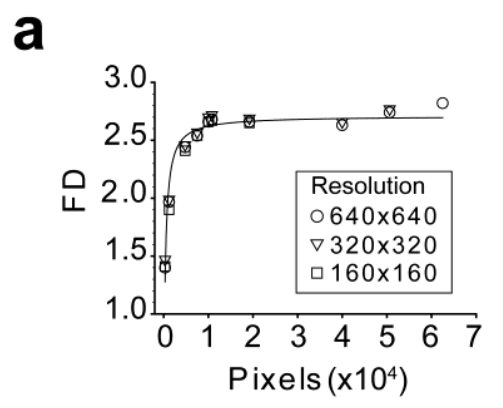

b

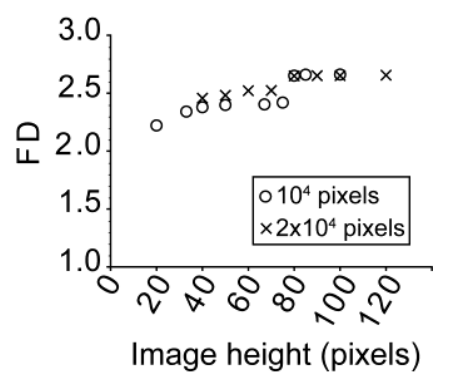

Lothaire et al., Figure 4

Figure 4: Assessment of the method limits using the Brodatz D03 texture image

The importance of the image size (a) and the height over length ratio (b) was evaluated. The image was iteratively and symmetrically fractionated in smaller parts and the FD of each fragment was calculated using the algorithm. The mean FD is plotted against the fragment image size (a) or image height (b). In panel A, the Brodatz D03 texture was analyzed using different starting resolution as indicated. In panel B, image fragments from the 640x640 image were analyzed as indicated.

a

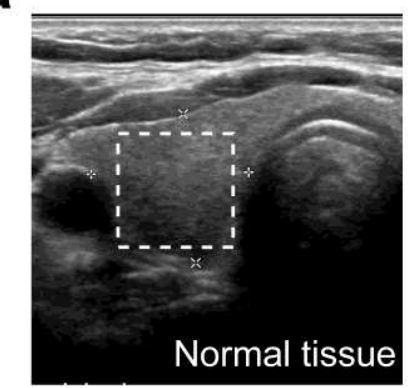

c

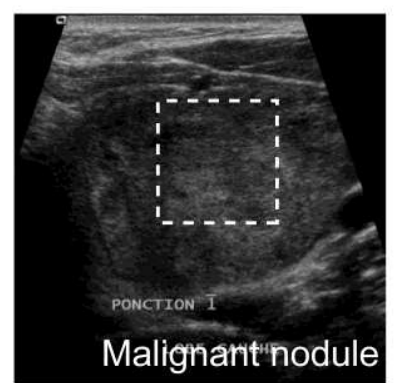

b

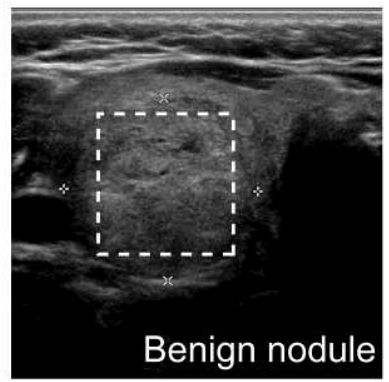

d

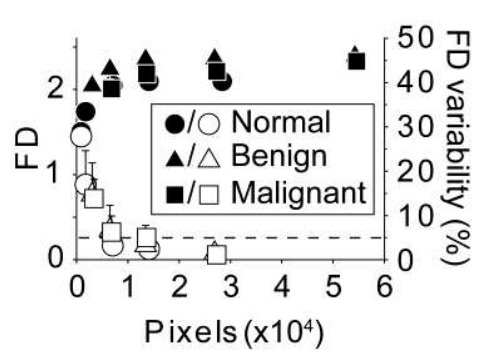

Pixels $\left(x 10^{4}\right)$

\section{Lothaire et al., Figure 5}

Figure 5: Assessment of the method using the US images

FD was calculated using images of normal thyroid tissue (a), benign nodule (b) and malignant nodule (c). The boxed regions within the full size US $(a, b, c)$ indicate the areas selected for FD calculation 
(d). The so-obtained images (a : 169x168; b : 228x238; c : 125x128) were iteratively and symmetrically fractionated and the FD of each fragment was calculated using the algorithm. The mean FD is plotted (solid symbols) against the fragment image size (d). The standard deviations of the FD are indicated. Open symbols represent the mean delta between the FD of the fragments and the FD of the full size area (last solid symbol). The error bar on open symbols correspond to the maximum delta. The dashed line represents the $5 \%$ variability level.

\section{$\underline{\text { FD calculation of thyroid US images }}$}

The FD of the images of 13 benign thyroid nodules, 14 malignant thyroid nodules and the neighbouring normal thyroid tissues was calculated using the algorithm (Tables 1\&2). The median FD of images corresponding to benign nodules was $2.2146(2.146 / 2.251)$ and, the median FD of malignant nodules, 2.310 (2.259/2.361). The median FD of the corresponding normal thyroid tissues were $2.231(2.098 / 2.288[25 \% / 75 \%])$ and $2.184(2.117 / 2.235$ [25\%/75\%]) respectively. While the FD of benign nodules was not statistically different from the FD of the corresponding normal tissue ( $p=0.78$; Fig. 6a), the FD of malignant nodules was statistically different from normal tissue (p<0.001; Fig. 6b).

The Delta FD calculated as the FD of the nodules minus the FD the corresponding normal tissue is presented in figure 6c. While the Delta FD of all the malignant nodules of the present study were strictly positive, the Delta FD of the benign nodules were evenly distributed around the zero value (Fig. 6c).
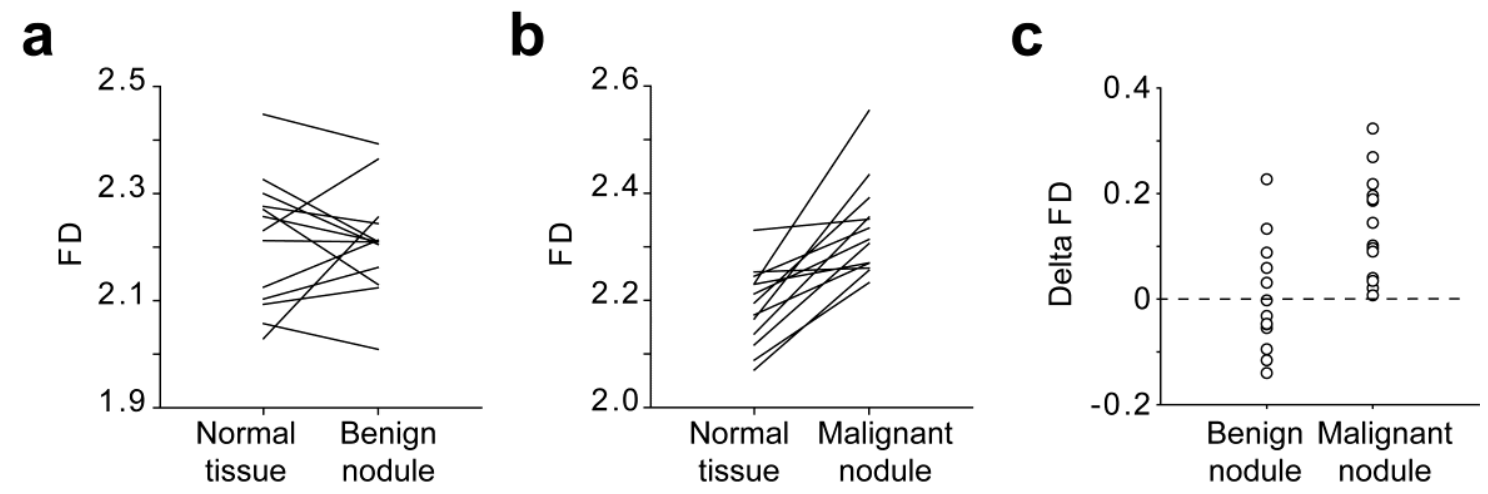

\section{Lothaire et al., Figure 6}

Figure 6: Comparison of the FD of normal thyroid tissue, benign nodule and malignant nodule US images from patients with benign nodules $(a ; n=13)$ and malignant nodules $(b ; n=14)$ were analysed using the algorithm. The FD of each nodule was compared to the FD of the adjacent normal 
tissue. The Delta FD between the FD of the nodules and the FD of the corresponding normal tissue was calculated as follow $\Delta \mathrm{FD}=\mathrm{FD}_{\text {nodule }}-\mathrm{FD}_{\text {normal }}$ and plotted in panel $\mathrm{c}$. 


\section{Discussion}

A thyroid US is recommended in the assessment of any suspected thyroid nodule detected by palpation or another imaging modality (computed tomography, magnetic resonance imaging, $18 \mathrm{~F}-$ fluorodeoxyglucose positron emission tomography, technetium Tc 99m sestamibi scan) (15-17). Echogenicity of homogeneous normal thyroid parenchyma appears increased in relation to the adjacent muscles but the echotexture of a nodule may be homogeneous or heterogeneous and is not a helpful finding in distinguishing malignant nodules from benign nodules (18). Thus, no differences between the US features (size and echogenicity) of benign and malignant nodules have been reported to date (19).

Although the majority of papillary carcinoma are currently diagnosed by US and cytological findings of FNAB, the preoperative discrimination between benign and malignant follicular tumour is still difficult (20). As it is the less frequent of the differentiated thyroid carcinomas, the sample size of the present retrospective study was restricted to 13 benign and 14 malignant nodules only. Using the simple and cost-effective thyroid US, we made use of the fractal dimension of the US images in order to discriminate benign and malignant nodules using the objective measure of the FD. Other techniques have previously been used in order to improve the discriminatory power of the US. Shao and col. (21) suggested that the combination of ultrasonic scores and elasticity scores could be an alternative to obtain higher sensitivity and specificity in the diagnosis of malignant thyroid nodules. However, the results rely on the observer's experience. Similarly, acoustic radiation force impulse (ARFI), a newer ultrasound elastography technique that evaluates the tissue stiffness qualitatively and quantitatively, seems to be helpful to predict malignant thyroid lesions but has many limitations due to technical factors $(22,23)$. Unfortunately, only a minority of follicular carcinomas are included in these studies. Here, because echographic examinations were performed on standard US devices and by different radiologists, the images selected for the studies were unlikely to be observer-dependent and the procedure could be easily applied in any care center. 
Our analysis pointed at the importance of the size of the images and the existence of a threshold value for the size of the image as a whole and for the length of each side, threshold beyond which the value of the measured FD was stable and close to the known FD value in the case of the reference images. Using the algorithm, the threshold varied between images, being around 7 000 pixels $^{2}$ for homogeneous images (normal thyroid tissue) and 10000 pixels $^{2}$ for heterogeneous images (benign and malignant nodules). The minimal values of surface and length reported here are easily achievable in clinical practice using regular US devices.

In this study, we reported the increased FD value of malignant thyroid nodules compared to normal tissue, while benign nodules and normal tissue could not be distinguished using this parameter. We postulated that the grayscale levels of each pixel would bring supplementary information and therefore should not be discarded. Therefore, we chose to convert the 2D US image to the 3D object that includes information about each pixel gray level. The main advantage of such a procedure is the lack of preliminary transformation of the image on contrary to previous reports that focused on objects boundaries $(12,24)$. Our strategy has proven accurate on reference images. Finally, our observation is in accordance to the fact that the rougher the appearance of the image, the larger the FD value, which fitted with the qualitative examination of the US images. Nevertheless, since FD is not able to completely capture the complexity of a image, two different objects may have an identical FD. Therefore inter-sample comparison was not meaningful and the comparison of normal and pathologic tissues is mandatory for an accurate evaluation of the malignancy of the nodule. The Delta FD between nodule and normal tissue is a promising candidate for diagnostic purpose. Thus, in the present study, only benign nodules showed a negative Delta FD and we could have identified $61 \%$ of the studied benign nodules using this threshold.

The preliminary results of this study showed that FD could be an additional discriminating feature between benign and malignant thyroid nodules. Further work will implement these first results on a broad scale by evaluating the algorithm on a larger database of native thyroid US images and correlating our findings with the known US patterns. 


\section{$\underline{\text { Methods }}$}

\section{Clinical data}

All US thyroid images were retrospectively reviewed with approval of the ethic committee from CHU Charleroi (OM008) under Eudract B325201526259. All experiments were performed in accordance with relevant guidelines and regulations. As a retrospective study, there was no need to obtain informed consent.

US examinations were performed by 4 different experienced radiologists, using Siemens ACUSON Antares, Philips iU22 and Philips EPIQ 5G ultrasound systems, with 5 to $12 \mathrm{MHz}$ multifrequency probes.

The images corresponded to 2 group of patients. The first group of 13 patients with thyroid follicular carcinoma underwent a total thyroidectomy at the CHU Vésale from July 2009 to September 2013 (Table 1). There were 7 females and 6 males; the median age was 39.6 (from 10 to 69 years) and 1 patient had 2 malignant nodules. FNAB was performed in 10 cases but cancer was never diagnosed preoperatively. Definitive histopathology was reviewed by one experienced endocrine pathologist. The second group of 11 patients underwent a thyroid loboisthmectomy for a single benign unilateral nodule between November 2010 and July 2014 (Table 2). There were 8 females and 3 males; the median age was 41.2 (from 17 to 54 years). Two supplementary benign nodules were identified in the contralateral lobe of the thyroid of 2 patients from the first group operated for malignant nodule (patients $\mathrm{n}^{\circ} 1$ and 4 , see Table 1). FNAB was performed preoperatively for the 11 single nodules.

\section{$\underline{\text { Image analyses }}$}

Original native images, issued from the database, were recorded in Tagged Image File Format (TIFF). Due to technical limitations of Matlab algorithms, images were converted to JPEG format with minimum compression. Sizes of all images are displayed in table 2. When multiple images were available, selection was performed as follow. Images where the zone of 
interest was partly masked by annotations were excluded. The image showing the largest view of the zone of interest was selected for further analysis.

The algorithm used for the measure of the FD (see Supplemental Material) was based on the Matlab software programming language and the Image Processing Toolbox (http://nl.mathworks.com/). The original image was converted to gray-scale and cropped to restrict the analysis to the relevant zone. The FD was calculated using the box-counting method (25): the principle is to cover an image $\mathrm{J}$ with a grid whose mesh size is hereby name $\mathrm{r}$, to count the number $\mathrm{N}$ of boxes which are covering the object and repeat the calculation by shrinking the size $(r)$ of the boxes. The FD of an image is defined as $D=\lim _{r}>0 \log \left(N_{r}\right) / \log (1 / r)$. The image normalization to 256 gray levels determined the "height" of the image, seen as a fractal embedded in a 3D space (Fig. 1). The quantity $\mathrm{N}_{\mathrm{r}}$ is thus the number of boxes needed to cover such a fractal surface.

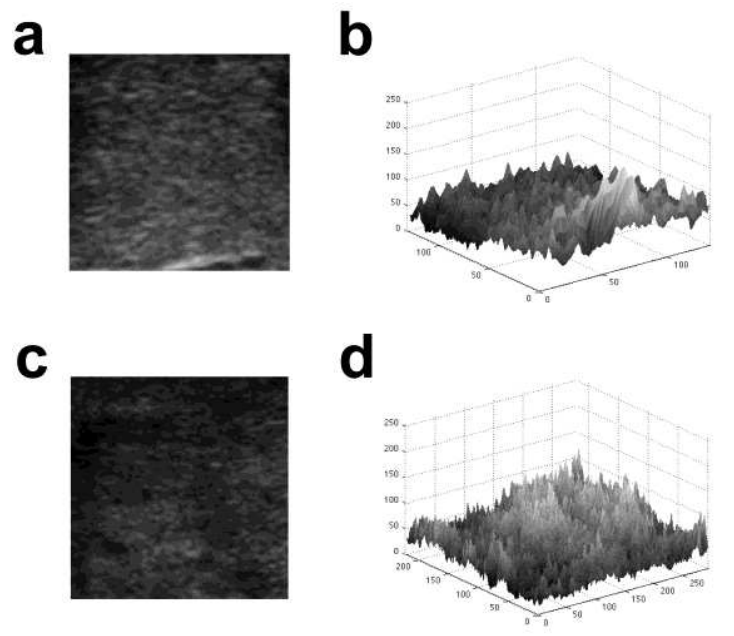

\section{Lothaire et al., Figure 1}

Figure 1: Conversion of 2D US image into 3D surface Images of benign (a) and malignant nodules (c) were converted into 3D surface using gray values of pixels ( $b$ and $d$ respectively) for fractal analysis. 
Data analyses

Statistical analyses of differences of FD between normal thyroid tissue and benign nodules on the one hand and normal thyroid tissue and malignant nodules on the other hand were performed with the Wilcoxon signed rank test. 


\section{Acknowledgments}

The authors thank the Radiology department and especially Mr Marique for giving access to US images. 


\section{$\underline{\text { References }}$}

1. Davies L., Welch HG. Increasing incidence of thyroid cancer in the United States, 19732002. JAMA. 295, 2164-2167 (2006).

2. Wiest PW, Hartshorne MF, Inskip PD, et al. Thyroid palpation versus high-resolution thyroid ultrasonography in the detection of nodules. J Ultrasound Med. 17, 487-496 (1998).

3. Cappelli C, Castellano M, Pirola I, et al. The predictive value of ultras ound findings in the management of thyroid nodules. QJM. 100, 29-35 (2007).

4. Kwak JY, Han KH, Yoon JH, et al. Thyroid imaging reporting and data system for US features of nodules: a step in establishing better stratification of cancer risk. Radiology. 260, 892899 (2011).

5. Kwak JY, Jung I, Baek JH, et al. Image reporting and characterization system for ultrasound features of thyroid nodules: multicentric Korean retrospective study. Korean J Radiol. 14, 110-117 (2013).

6. Friedrich-Rust M, Meyer G, Dauth N, et al. Interobserver Agreement of Thyroid Imaging Reporting and Data System (TIRADS) and Strain Elastography for the Assessment of Thyroid Nodules. PLoS One. 8, e77927 (2013).

7. Merino S, Arrazola J, Cardenas A, et al. Utility and interobserver agreement of ultrasound elastography in the detection of malignant thyroid nodules in clinical care. AJNR Am J Neuroradiol. 32, 2142-2148 (2011).

8. Sillery JC, Reading CC, Charboneau JW, et al. Thyroid follicular carcinoma: sonographic features of 50 cases. AJR Am J Roentgenol. 194, 44-54 (2010).

9. Kamiya A, Takahashi T. Quantitative assessments of morphological and functional properties of biological trees based on their fractal nature. J Appl Physiol (1985). 102, 2315-2323 (2007).

10. Karshafian R, Burns PN, Henkelman MR. Transit time kinetics in ordered and disordered vascular trees. Phys Med Biol. 48, 3225-3237 (2003). 
11. Grauslund J, Green A, Kawasaki R, et al. Retinal vascular fractals and microvascular and macrovascular complications in type 1 diabetes. Ophthalmology. 117, 1400-1405 (2010).

12. Fiz JA, Monte-Moreno E, Andreo F, et al. Fractal dimension analysis of malignant and benign endobronchial ultrasound nodes. BMC Med Imaging. 14, 22 (2014).

13. Lee WL HK. A robust algorithm for the fractal dimension of images and its applications to the classification of natural images and ultrasonic liver images. Signal Processing. 90, 1894-1904 (2010).

14. Novianto S SY, Maeda J near optimum estimation of local fractal dimension for image segmentation. Pattern Recognition Letters. 24, 365-374 (2003).

15. Gharib H, Papini E, Valcavi R, et al. American Association of Clinical Endocrinologists and Associazione Medici Endocrinologi medical guidelines for clinical practice for the diagnosis and management of thyroid nodules. Endocr Pract. 12, 63-102 (2006).

16. Bastin S, Bolland MJ, Croxson MS. Role of ultrasound in the assessment of nodular thyroid disease. J Med Imaging Radiat Oncol. 53 177-187 (2009).

17. Pacini F, Castagna MG, Brilli L, et al. Differentiated thyroid cancer: ESMO clinical recommendations for diagnosis, treatment and follow-up. Ann Oncol. 20, 143-146 (2009).

18. Moon WJ, Jung SL, Lee JH, et al. Benign and malignant thyroid nodules: US differentiation--multicenter retrospective study. Radiology. 247 762-770 (2008).

19. Samulski TD, Shutty C, LiVolsi VA, et al. The reliability of thyroid nodule ultrasound features and size to predict malignancy in fine needle aspiration specimens: Practical utility for the evaluating pathologist. Diagn Cytopathol. 43, 471-477 (2015).

20. Miyakawa M, Onoda N, Etoh M, et al. Diagnosis of thyroid follicular carcinoma by the vascular pattern and velocimetric parameters using high resolution pulsed and power Doppler ultrasonography. Endocr J. 52, 207-212 (2005). 
21. Shao J., Shen Y. \& Wang J. Ultrasound scoring in combination with ultrasound elastography for differentiating benign and malignant thyroid nodules. Clinical Endocrinology. 83, 254-260 (2015).

22. Zhuo J., Ma Z., Fu WJ. \& Liu SP. Differentiation of benign from malignant thyroid nodules with acoustic radiation force impulse technique. Br J Radiol. 87, 1035:20130263 (2014).

23. Xu JM, Xu XH, Xu HX, et al. Conventional US, US elasticity imaging, and acoustic radiation force impulse imaging for prediction of malignancy in thyroid nodules. Radiology. 272, $577-586(2014)$.

24. Kikuchi A, Kozuma S, Sakamaki K, et al. Fractal tumor growth of ovarian cancer: sonographic evaluation. Gynecol Oncol. 87, 295-302 (2002).

25. Li J, Du Q, Sun C. An improved box-counting method for image fractal dimension estimation. Pattern Recognition. 42, 2460-2469 (2009). 
Table 1: Clinical data and corresponding image information (malignant nodule group)

\begin{tabular}{|c|c|c|c|c|c|c|c|c|c|c|c|}
\hline \multirow[t]{2}{*}{ Patient } & \multirow[t]{2}{*}{ Sex } & \multirow[t]{2}{*}{ Age } & \multirow{2}{*}{$\begin{array}{l}\text { Size of } \\
\text { nodule } \\
(\mathrm{mm})\end{array}$} & \multirow[t]{2}{*}{ US characteristics } & \multirow{2}{*}{$\begin{array}{l}\text { FNA } \\
\mathrm{B}(1)\end{array}$} & \multirow{2}{*}{$\begin{array}{l}\text { Histology } \\
(2)\end{array}$} & \multirow[t]{2}{*}{ pTN } & \multicolumn{2}{|c|}{ Image size in pixel (LxH) } & \multicolumn{2}{|c|}{ Fractal dimension } \\
\hline & & & & & & & & $\begin{array}{l}\text { Normal } \\
\text { tissue } \\
\text { image }\end{array}$ & $\begin{array}{l}\text { Malignant } \\
\text { nodule } \\
\text { image }\end{array}$ & $\begin{array}{l}\text { Normal } \\
\text { tissue } \\
\text { image }\end{array}$ & $\begin{array}{l}\text { Malignant } \\
\text { nodule } \\
\text { image }\end{array}$ \\
\hline 1 & $\mathrm{~F}$ & 42 & 9 & $\begin{array}{l}\text { Hypoechogenous, irregular, } \\
\text { microcalcifications }\end{array}$ & $\mathrm{NC}$ & FMI & pT1aNx & $\begin{array}{l}18928 \\
(112 \times 169)\end{array}$ & $\begin{array}{l}11662 \\
(119 \times 98)\end{array}$ & 2.2121 & 2.3138 \\
\hline 2 & $\mathrm{M}$ & 69 & 30 & $\begin{array}{l}\text { Hypoechogenous, peripheral and central } \\
\text { vascularization }\end{array}$ & FP & FMI & pT2Nx & $\begin{array}{l}47872 \\
(272 \times 176)\end{array}$ & $\begin{array}{l}21546 \\
(189 \times 114)\end{array}$ & 2.1374 & 2.3354 \\
\hline 3 & $\mathrm{M}$ & 50 & 40 & $\begin{array}{l}\text { Hypoechogenous, heterogeneous, } \\
\text { microcalcifications }\end{array}$ & FP & FMI & pT2Nx & $\begin{array}{l}17914 \\
(169 \times 106)\end{array}$ & $\begin{array}{l}63054 \\
(226 \times 279)\end{array}$ & 2.1729 & 2.2693 \\
\hline 4 & $\mathrm{M}$ & 46 & 20 & Solid, hypervascularization & NA & FMI & pT2Nx & $\begin{array}{l}13578 \\
(146 \times 93)\end{array}$ & $\begin{array}{l}15125 \\
(121 \times 125)\end{array}$ & 2.2312 & 2.5543 \\
\hline 5 & $\mathrm{M}$ & 43 & 45 & $\begin{array}{l}\text { Hypoechogenous, heterogeneous, } \\
\text { calcifications, peripheral and central } \\
\text { vascularization }\end{array}$ & FP & FMI & pT3Nx & $\begin{array}{l}17423 \\
(133 \times 131)\end{array}$ & $\begin{array}{l}64240 \\
(292 \times 220)\end{array}$ & 2.1654 & 2.4343 \\
\hline 6 & $\mathrm{~F}$ & 37 & 13 & $\begin{array}{l}\text { Hypoechogenous, regular, peripheral } \\
\text { vascularization }\end{array}$ & FP & FMI & pT1Nx & $\begin{array}{l}21777 \\
(183 \times 119)\end{array}$ & $\begin{array}{l}12519 \\
(117 \times 107)\end{array}$ & 2.3309 & 2.3515 \\
\hline 7 & $\mathrm{~F}$ & 34 & 20 & Heterogeneous, hypervascularization & NA & FMI & pT2Nx & $\begin{array}{l}19043 \\
(139 \times 137)\end{array}$ & $\begin{array}{l}34138 \\
(202 \times 169)\end{array}$ & 2.0700 & 2.2561 \\
\hline 8 & $\mathrm{~F}$ & 10 & 30 & $\begin{array}{l}\text { Hypoechogenous, regular, peripheral } \\
\text { vascularization }\end{array}$ & FP & FMI & pT2Nx & $\begin{array}{l}10416 \\
(112 \times 93)\end{array}$ & $\begin{array}{l}24570 \\
(195 \times 126)\end{array}$ & 2.1951 & 2.3913 \\
\hline 9 & $\mathrm{~F}$ & 36 & 15 & $\begin{array}{l}\text { Hypoechogenous, heterogeneous, } \\
\text { peripheral and central vascularization }\end{array}$ & FP & PFP & pT1bNx & $\begin{array}{l}13231 \\
(131 \times 101)\end{array}$ & $\begin{array}{l}10670 \\
(110 \times 97)\end{array}$ & 2.0884 & 2.2330 \\
\hline 10 & $\mathrm{~F}$ & 30 & 30 & $\begin{array}{l}\text { Hypoechogenous, heterogeneous, } \\
\text { calcifications, peripheral and central } \\
\text { vascularization }\end{array}$ & FP & FMI & $\mathrm{pT} 2 \mathrm{Nx}$ & $\begin{array}{l}22446 \\
(258 \times 87)\end{array}$ & $\begin{array}{l}37000 \\
(200 \times 185)\end{array}$ & 2.2539 & 2.2602 \\
\hline 11 & $\mathrm{~F}$ & 14 & $\begin{array}{l}20 \\
9\end{array}$ & $\begin{array}{l}\text { Hyperechogenous, central vascularization } \\
\text { Isoechogenous, irregular, peripheral } \\
\text { vascularization }\end{array}$ & $\begin{array}{l}\mathrm{C} \\
\mathrm{C}\end{array}$ & $\begin{array}{l}\text { PFP } \\
\text { PFP }\end{array}$ & pT2Nx & $\begin{array}{l}13365 \\
(135 \times 99) \\
13365 \\
(135 \times 99)\end{array}$ & $\begin{array}{l}14868 \\
(126 \times 118) \\
28305 \\
(185 \times 153)\end{array}$ & 2.1168 & $\begin{array}{l}2.3065 \\
2.1512\end{array}$ \\
\hline 12 & M & 64 & 40 & $\begin{array}{l}\text { Hypoechogenous, heterogeneous, } \\
\text { peripheral and central vascularization }\end{array}$ & NA & FC & pT3Nx & $\begin{array}{l}12610 \\
(130 \times 97)\end{array}$ & $\begin{array}{l}103488 \\
(336 \times 308)\end{array}$ & 2.2450 & 2.3356 \\
\hline 13 & $\mathrm{M}$ & 40 & 20 & $\begin{array}{l}\text { Hypoechogenous, peripheral and central } \\
\text { vascularization }\end{array}$ & NA & FMI & pT1Nx & $\begin{array}{l}15876 \\
(189 \times 84)\end{array}$ & $\begin{array}{l}11770 \\
(110 \times 107)\end{array}$ & 2.2326 & 2.2704 \\
\hline
\end{tabular}

(1) NC, not conclusive; FP, Follicular proliferation; NA, Not applicable; C, Colloid

(2) FMI, Follicular minimal invasive; PFP, Papillary with follicular presentation; FC, Follicular carcinoma 
Table 2: Clinical data and corresponding image information (benign nodule group)

\begin{tabular}{|c|c|c|c|c|c|c|c|c|c|c|}
\hline \multirow[t]{2}{*}{ Patient } & \multirow[t]{2}{*}{ Sex } & \multirow[t]{2}{*}{ Age } & \multirow{2}{*}{$\begin{array}{l}\text { Size of } \\
\text { nodule( } \\
\text { mm) }\end{array}$} & \multirow[t]{2}{*}{ US characteristics } & \multirow{2}{*}{$\begin{array}{l}\text { FNA } \\
\text { B (1) }\end{array}$} & \multirow{2}{*}{$\begin{array}{l}\text { Histology } \\
\text { (2) }\end{array}$} & \multicolumn{2}{|c|}{ Image size in pixel $(\mathrm{LxH})$} & \multicolumn{2}{|c|}{ Fractal dimension } \\
\hline & & & & & & & $\begin{array}{l}\text { Normal } \\
\text { tissue } \\
\text { image }\end{array}$ & $\begin{array}{l}\text { Malignant } \\
\text { nodule } \\
\text { image }\end{array}$ & $\begin{array}{l}\text { Normal } \\
\text { tissue } \\
\text { image }\end{array}$ & $\begin{array}{l}\text { Benign } \\
\text { nodule } \\
\text { image }\end{array}$ \\
\hline 1 & $\mathrm{~F}$ & 42 & 13 & $\begin{array}{l}\text { Hypoechogenous, peripheral } \\
\text { vascularization }\end{array}$ & NA & $\mathrm{B}$ & $\begin{array}{l}18928 \\
(112 \times 169)\end{array}$ & $\begin{array}{l}18414 \\
(186 \times 99)\end{array}$ & 2.2121 & 2.2097 \\
\hline 4 & $\mathrm{M}$ & 46 & 20 & Necrotic & NA & $\mathrm{CD}$ & $\begin{array}{l}13578 \\
(146 \times 93)\end{array}$ & $\begin{array}{l}10340 \\
(110 \times 96)\end{array}$ & 2.2312 & 2.3643 \\
\hline 14 & $\mathrm{~F}$ & 17 & 30 & Heterogeneous, necrosis & $\mathrm{C}$ & FA & $\begin{array}{l}16383 \\
(129 \times 127)\end{array}$ & $\begin{array}{l}23973 \\
(183 \times 131)\end{array}$ & 2.103 & 2.162 \\
\hline 15 & $\mathrm{M}$ & 45 & 34 & $\begin{array}{l}\text { Hypoechogenous, calcifications, regular, } \\
\text { peripheral and central vascularization }\end{array}$ & FP & FA & $\begin{array}{l}14525 \\
(175 \times 83)\end{array}$ & $\begin{array}{l}25020 \\
(180 \times 139)\end{array}$ & 2.2762 & 2.2446 \\
\hline 16 & $\mathrm{M}$ & 38 & 35 & $\begin{array}{l}\text { Hypoechogenous, peripheral and central } \\
\text { vascularization }\end{array}$ & FP & $\mathrm{MiA}$ & $\begin{array}{l}22168 \\
(163 \times 136)\end{array}$ & $\begin{array}{l}13184 \\
(128 \times 103)\end{array}$ & 2.0299 & 2.2564 \\
\hline 17 & $\mathrm{~F}$ & 39 & 56 & $\begin{array}{l}\text { Iso -and hypoechogenous, peripheral and } \\
\text { central vascularization }\end{array}$ & $\mathrm{C}$ & $\mathrm{C}$ & $\begin{array}{l}19795 \\
(185 \times 107)\end{array}$ & $\begin{array}{l}54264 \\
(228 \times 238)\end{array}$ & 2.4482 & 2.3938 \\
\hline 18 & $\mathrm{~F}$ & 42 & 17 & $\begin{array}{l}\text { Hypoechogenous, peripheral } \\
\text { vascularization }\end{array}$ & FP & $\mathrm{MaA}$ & $\begin{array}{l}23405 \\
(155 \times 151)\end{array}$ & $\begin{array}{l}20880 \\
(144 \times 145)\end{array}$ & 2.0574 & 2.0094 \\
\hline 19 & $\mathrm{~F}$ & 40 & 30 & $\begin{array}{l}\text { Hypoechogenous, heterogeneous, } \\
\text { microcalcifications, peripheral and } \\
\text { central vascularization }\end{array}$ & SFP & MG & $\begin{array}{l}17907 \\
(141 \times 127)\end{array}$ & $\begin{array}{l}18492 \\
(134 \times 138)\end{array}$ & 2.3262 & 2.2106 \\
\hline 20 & $\mathrm{~F}$ & 53 & 15 & $\begin{array}{l}\text { Irregular, peripheral and central } \\
\text { vascularization }\end{array}$ & $\mathrm{C}$ & $\mathrm{MiA}$ & $\begin{array}{l}28392 \\
(169 \times 168)\end{array}$ & $\begin{array}{l}22576 \\
(166 \times 136)\end{array}$ & 2.0939 & 2.1246 \\
\hline 21 & $\mathrm{~F}$ & 41 & 50 & $\begin{array}{l}\text { Hypoechogenous, calcifications, } \\
\text { peripheral and central vascularization }\end{array}$ & FP & $\mathrm{MiA}$ & $\begin{array}{l}15908 \\
(97 \times 164)\end{array}$ & $\begin{array}{l}67599 \\
(261 \times 259) \\
\end{array}$ & 2.3007 & 2.2058 \\
\hline 22 & $\mathrm{~F}$ & 44 & 35 & $\begin{array}{l}\text { Hypo, hetero, calcific, periph and central } \\
\text { vascul }\end{array}$ & $\mathrm{C}$ & $\mathrm{C}$ & $\begin{array}{l}27029 \\
(179 \times 151)\end{array}$ & $\begin{array}{l}16124 \\
(139 \times 116)\end{array}$ & 2.2701 & 2.1305 \\
\hline 23 & $\mathrm{M}$ & 28 & 25 & $\begin{array}{l}\text { Hypoechogenous, peripheral and central } \\
\text { vascularization }\end{array}$ & FP & $\mathrm{MiA}$ & $\begin{array}{l}26352 \\
(183 \times 144)\end{array}$ & $\begin{array}{l}26316 \\
(204 \times 129)\end{array}$ & 2.1251 & 2.2136 \\
\hline 24 & $\mathrm{~F}$ & 54 & 31 & $\begin{array}{l}\text { Isoechogenous, peripheral } \\
\text { vascularization }\end{array}$ & $\mathrm{C}$ & $\mathrm{C}$ & $\begin{array}{l}22125 \\
(177 \times 125)\end{array}$ & $\begin{array}{l}13433 \\
(133 \times 101)\end{array}$ & 2.2576 & 2.2104 \\
\hline
\end{tabular}

(1) NA, Not applicable; C, Colloid; FP, Follicular proliferation; SFP, Stigmata of follicular proliferation

(2) B, Benign; CD, Cystic degeneration; FA, Follicular adenoma; MiA, Microfollicular adenoma; MaA, Macrofollicular adenoma; MG, Multinodular goiter; C, Colloid 


\section{Figures}
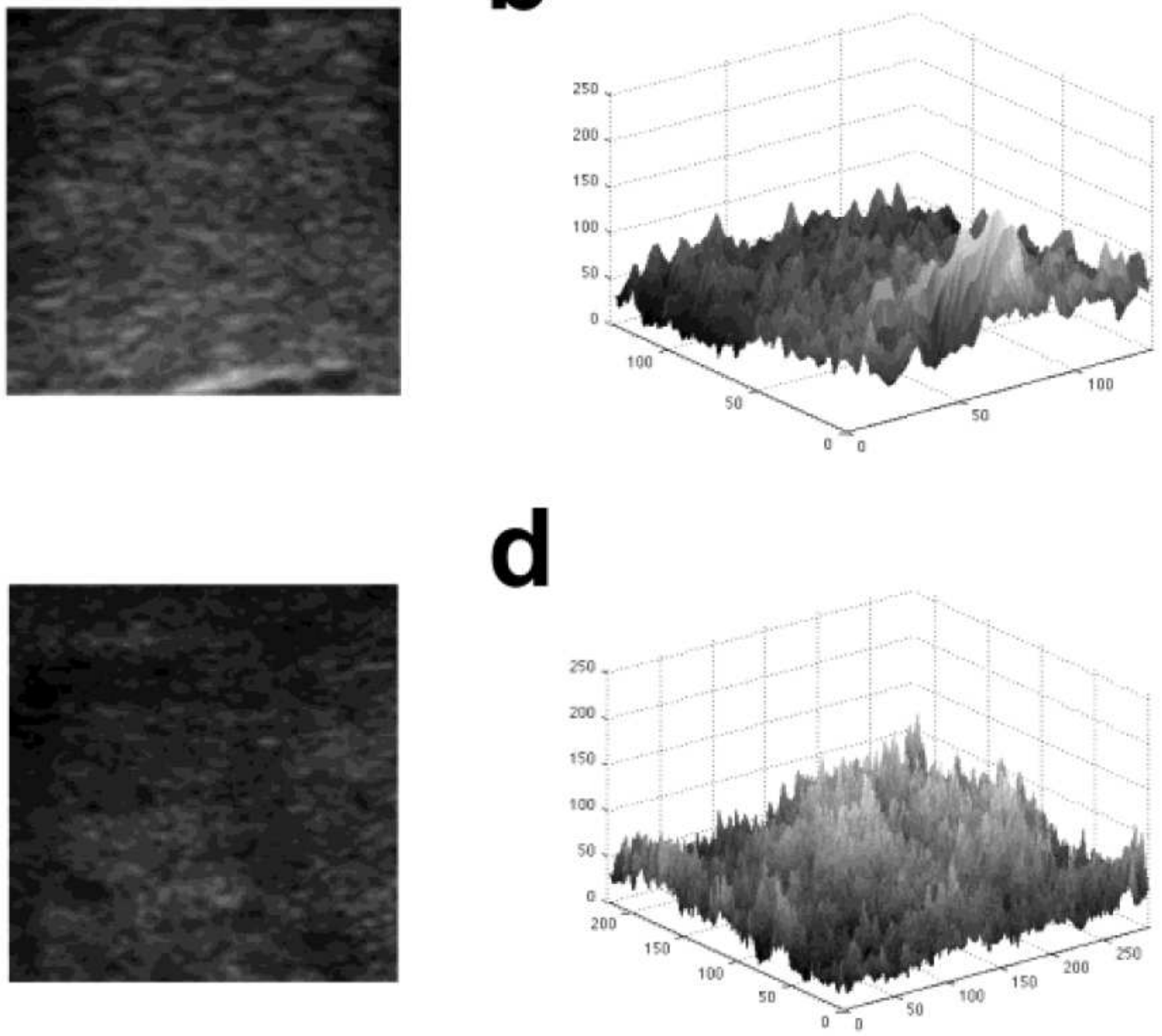

\section{Figure 1}

Conversion of 2D US image into 3D surface Images of benign (a) and malignant nodules (c) were converted into 3D surface using gray values of pixels ( $b$ and $d$ respectively) for fractal analysis. 
a

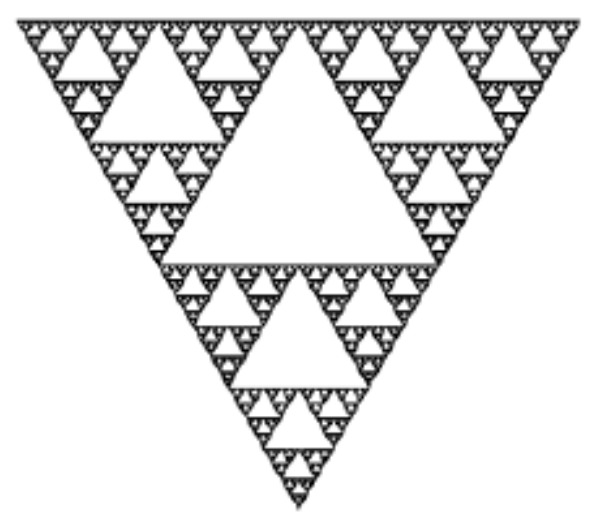

C

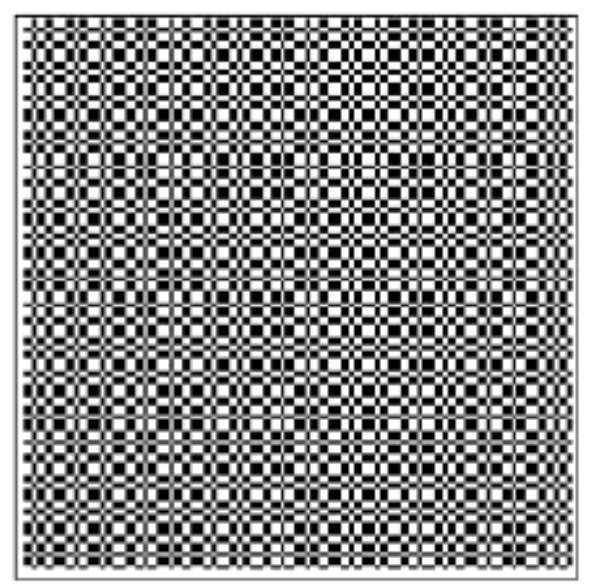

b

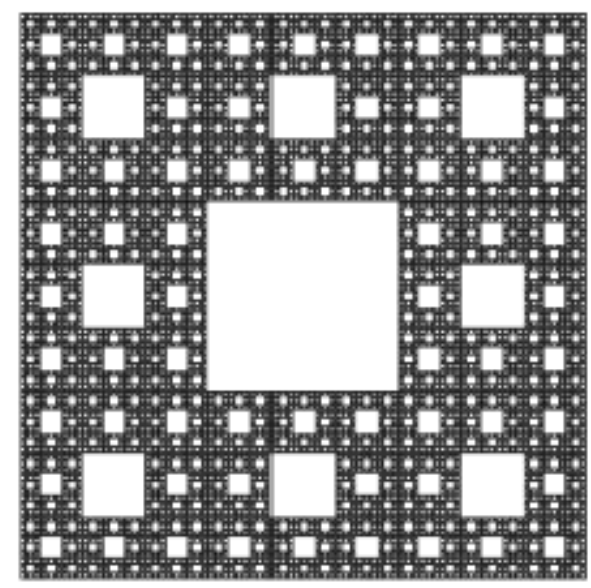

d

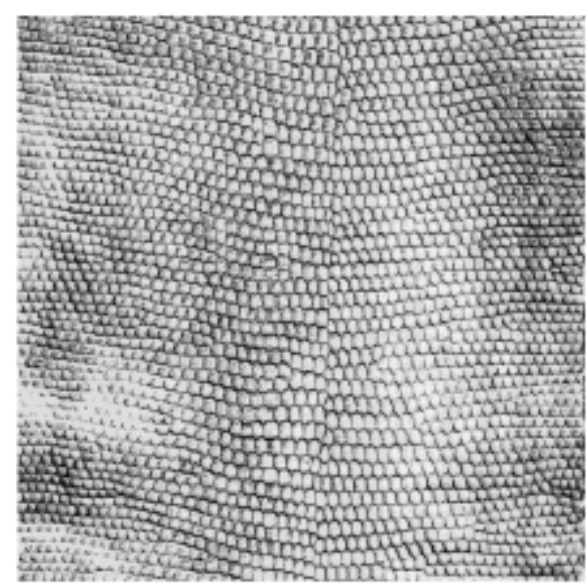

Figure 2

Figures selected to validate the algorithm (a) The Sierpinski triangle was built starting from a full equilateral triangle, divided into 4 equals smaller triangles and then, removing the "central one". Iterating this process yields a structure whose theoretical FD is 1.585. (b) The Sierpinski carpet was obtained by dividing a square into 9 smaller squares and then removing the "central one". The structure obtained by iterating the previous construction will have a theoretical FD of 1.89. (c) The Dragon curve is a spacefilling curve with a theoretical FD of 2.0. (d) The grayscale texture D03 which belongs to the standard Brodatz texture album has a FD varying from 2.60 till 2.69 (15). 
a

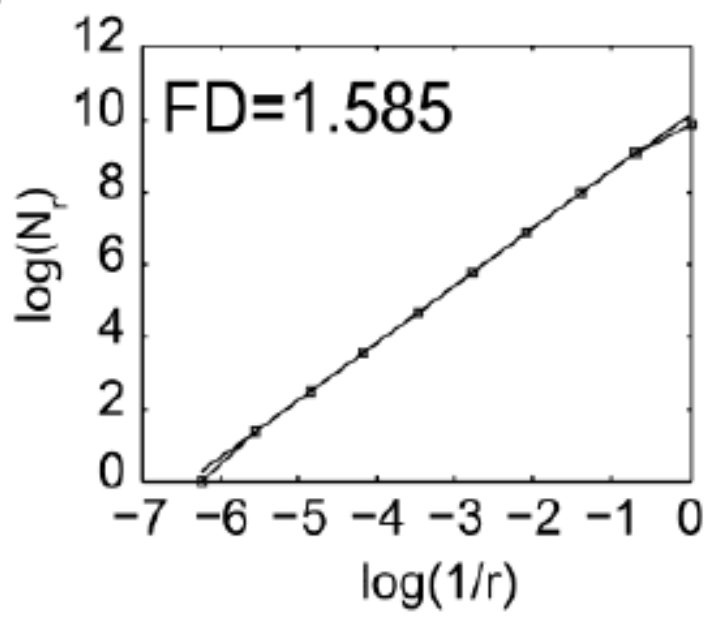

C

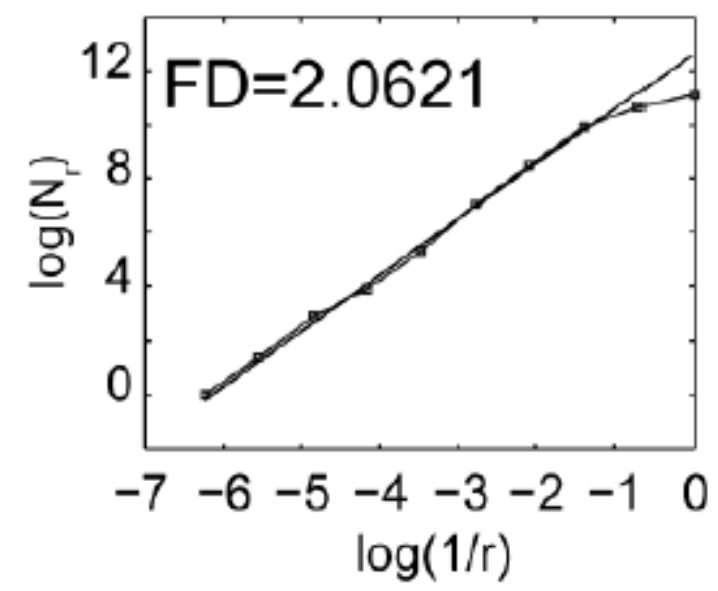

b

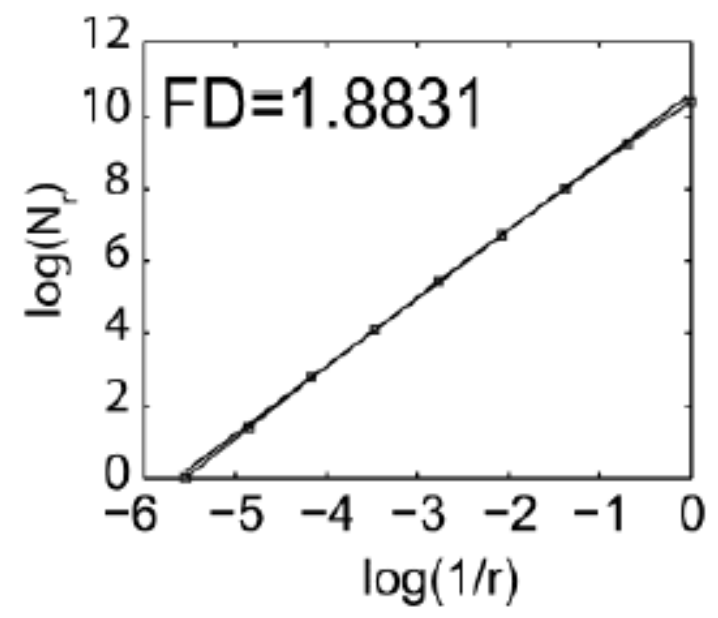

d

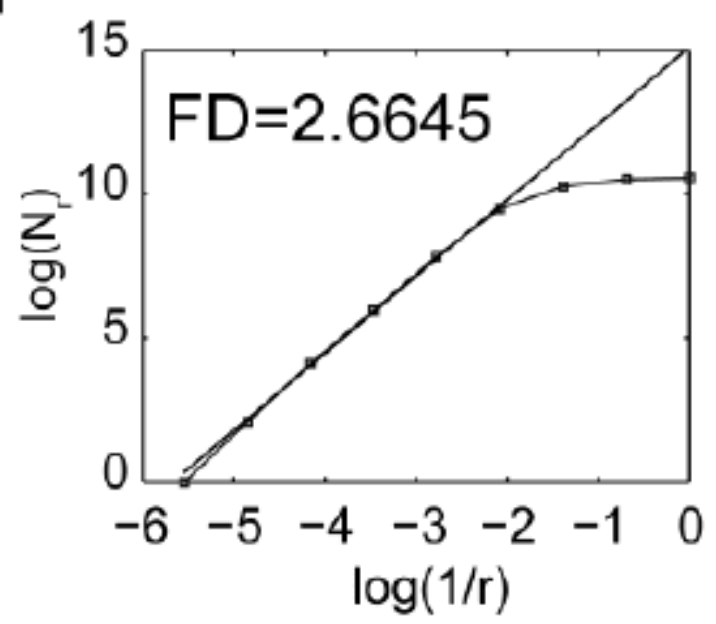

Figure 3

Measurement of the FD of reference images using the algorithm The FD values of the Sierpinski triangle (a), the Sierpinski carpet (b), the Dragon curve (c) and the Brodatz D03 texture (d) were calculated using the box counting method. The number of boxes $(\mathrm{N})$ required to cover the whole image is plotted against the reduction factor $(r)$ of the box sizes between each iteration of the analysis. The linear best fit of the $\log (N)=f(\log (1 / r))$ curve whose slope corresponds to the FD is represented. 

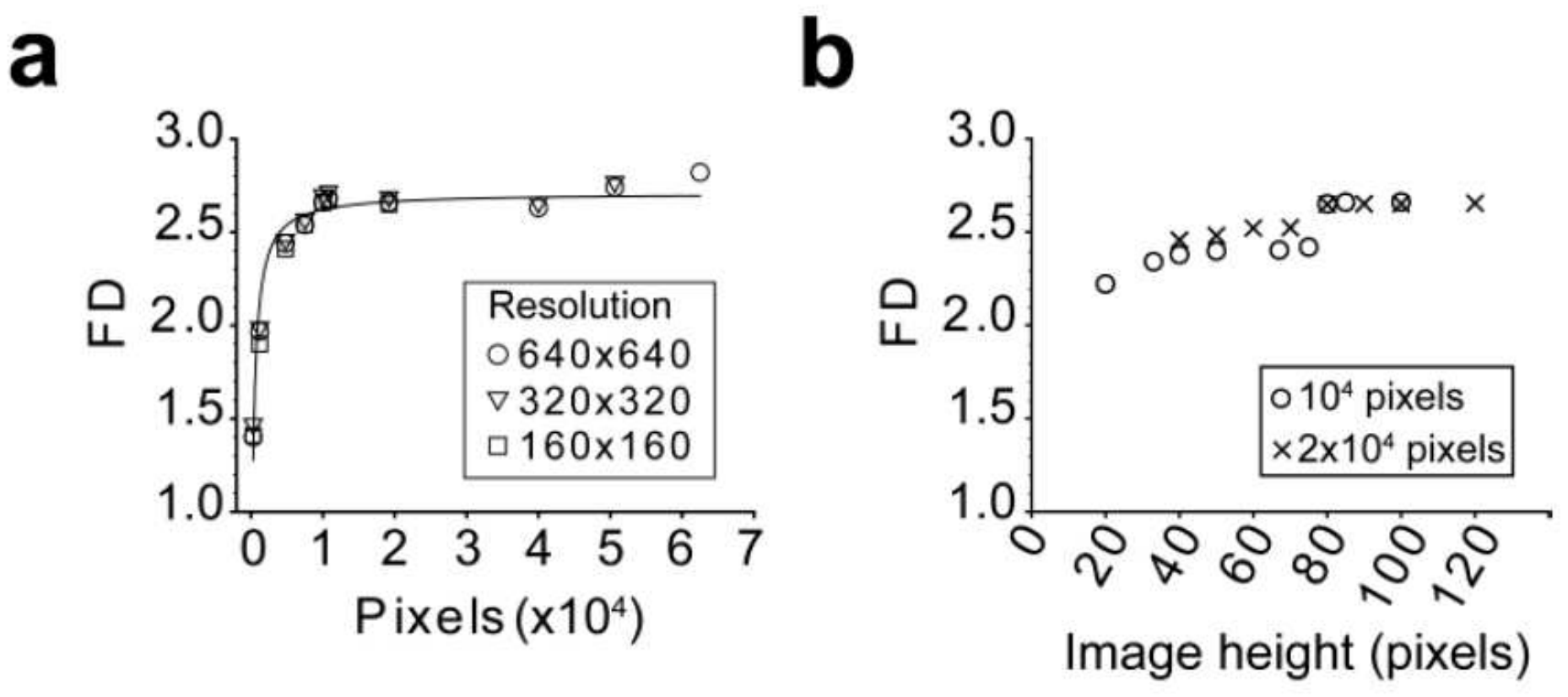

Figure 4

Assessment of the method limits using the Brodatz D03 texture image The importance of the image size (a) and the height over length ratio (b) was evaluated. The image was iteratively and symmetrically fractionated in smaller parts and the FD of each fragment was calculated using the algorithm. The mean FD is plotted against the fragment image size (a) or image height (b). In panel A, the Brodatz D03 texture was analyzed using different starting resolution as indicated. In panel $B$, image fragments from the $640 \times 640$ image were analyzed as indicated. 

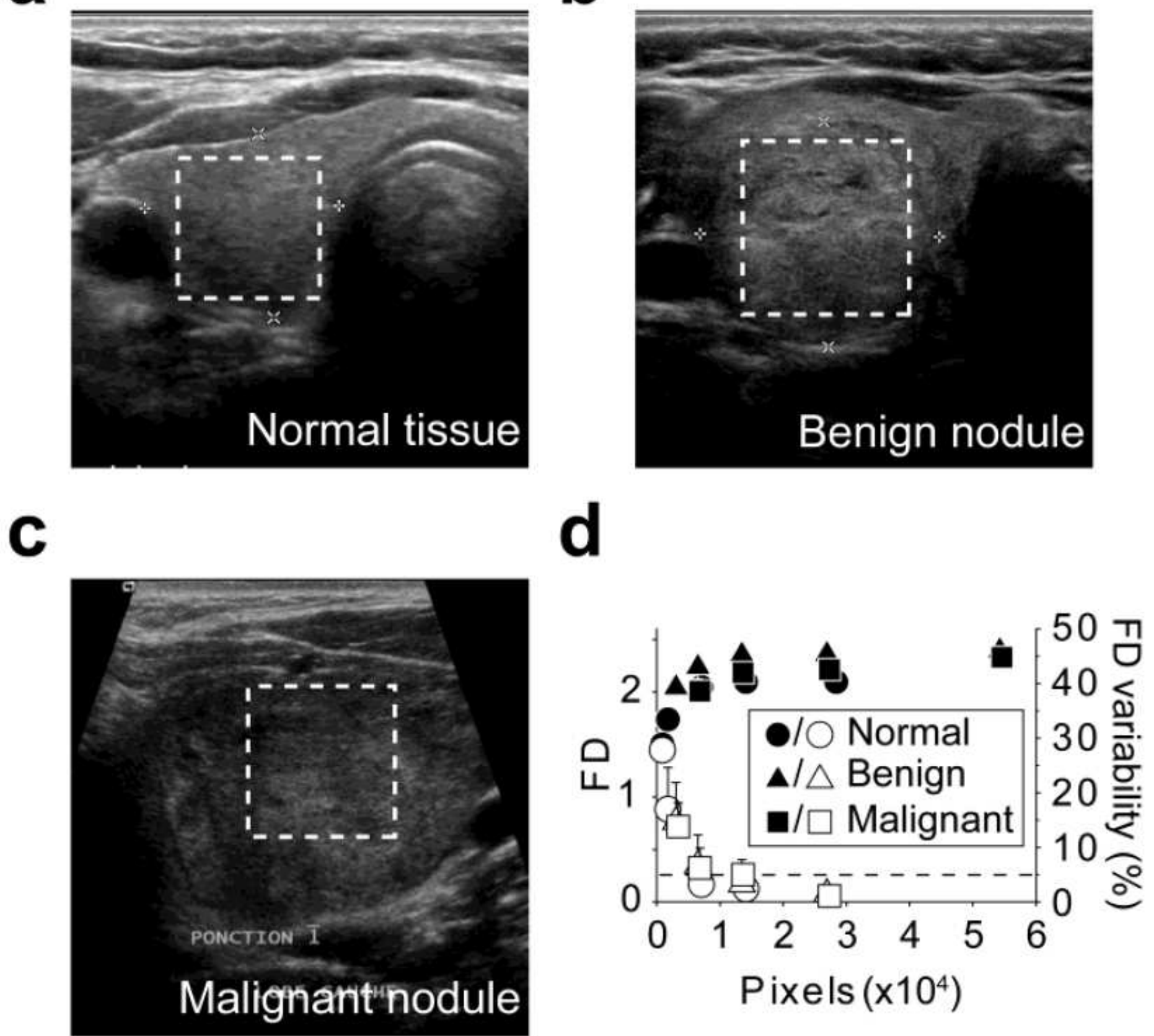

Figure 5

Assessment of the method using the US images FD was calculated using images of normal thyroid tissue (a), benign nodule (b) and malignant nodule (c). The boxed regions within the full size US $(a, b, c)$ indicate the areas selected for FD calculation (d). The so-obtained images (a : 169x168; b : 228x238; c : $125 \times 128)$ were iteratively and symmetrically fractionated and the FD of each fragment was calculated using the algorithm. The mean FD is plotted (solid symbols) against the fragment image size (d). The standard deviations of the FD are indicated. Open symbols represent the mean delta between the FD of the fragments and the FD of the full size area (last solid symbol). The error bar on open symbols correspond to the maximum delta. The dashed line represents the $5 \%$ variability level. 
a

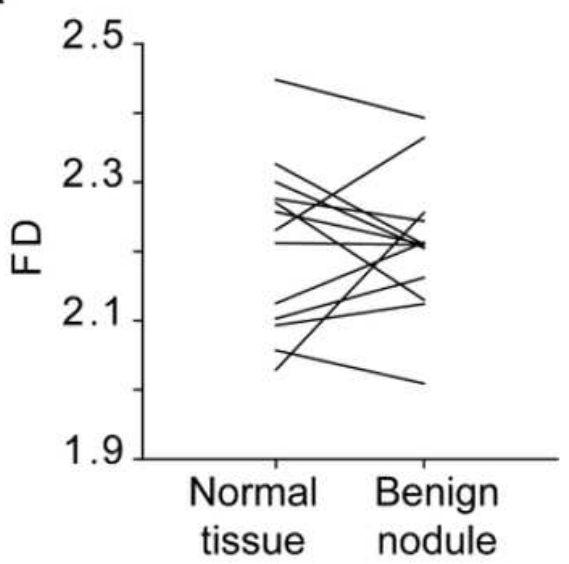

b

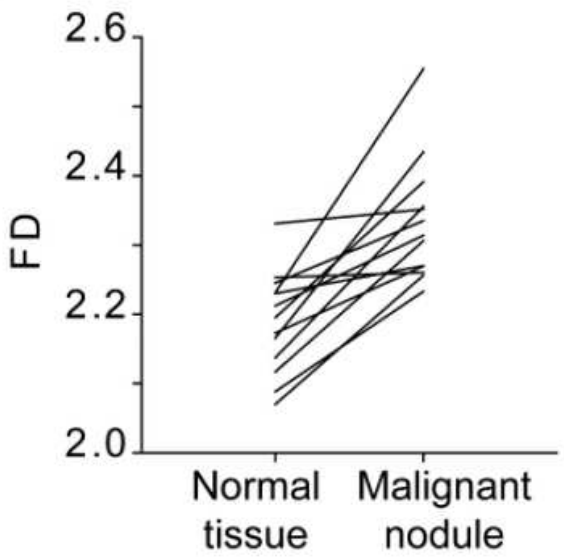

C

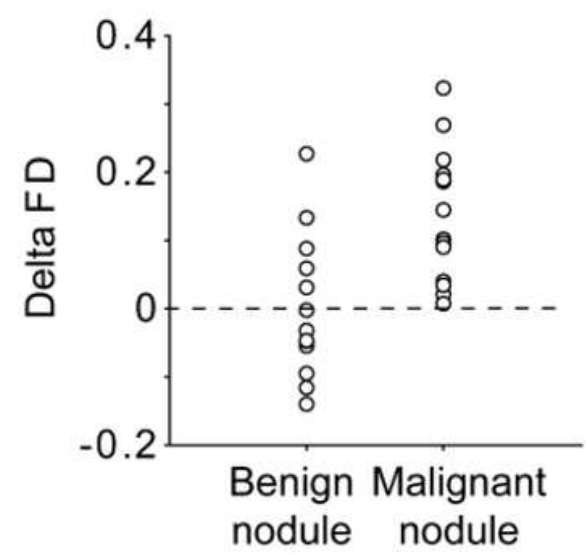

Figure 6

Comparison of the FD of normal thyroid tissue, benign nodule and malignant nodule US images from patients with benign nodules $(a ; n=13)$ and malignant nodules $(b ; n=14)$ were analysed using the algorithm. The FD of each nodule was compared to the FD of the adjacent normal tissue. The Delta FD between the FD of the nodules and the FD of the corresponding normal tissue was calculated as follow $\Delta \mathrm{FD}=\mathrm{FDnodule}-\mathrm{FDnormal}$ and plotted in panel $\mathrm{c}$. 